\title{
Macromolecular Polyradicals with Cyclic Triphosphazene as a Core. Spectral and Electrochemical Properties
}

\author{
Gabino A. Carriedo, ${ }^{* \dagger}$ Francisco J. García Alonso, ${ }^{\dagger}$ P. Gómez Elipe, ${ }^{\dagger}$ Enric Brillas, ${ }^{\ddagger}$ \\ Amilcar Labarta, "Luis Juliá ${ }^{* \#}$ \\ Departamento de Quimica Orgánica e Inorgánica, Universidad de Oviedo, Oviedo 33071, Spain, \\ Departament de Química Física i Departament de Física Fonamental, Universitat de Barcelona, Avgda. \\ Diagonal 647, 08028 Barcelona, Spain, Institut d'Investigacions Quimiques i Ambientals de Barcelona \\ (CSIC), Jordi Girona 18-26, 08034 Barcelona, Spain \\ ljbmoh@cid.csic.es
}

\begin{abstract}
Stable cyclotriphosphazenes $\mathbf{5}$ and $\mathbf{6}$, with three and four carbon radical centers, have been prepared by condensation of (4-hydroxy-2,6-dichlorophenyl)bis(2,4,6-trichlorophenyl)methyl radical (4) with tetrachloro-2,2'-dioxybiphenyl-cyclotriphosphazene (7). EPR studies of both polyradicals in fluid solution suggest an electronic communication through the PN multiple bonds of the cycle. EPR spectral results in frozen solutions and magnetic susceptibility measurements in the solid are consistent with very weak electron-electron dipolar interactions. Reductive cyclic voltammetry shows a single three-electron redox couple for triradical 5 and a single four-electron redox couple for tetraradical $\mathbf{6}$. Both polyradicals 5 and $\mathbf{6}$ have been chemically oxidized to a stable trication $\mathbf{5}^{\mathbf{3}^{+}}$and a tetracation $6^{4+}$, respectively, by electron transfer reactions.
\end{abstract}




\section{Introduction}

The spirocyclic phosphazenes ${ }^{1}$ are an important class of cyclophosphazenes that have received much attention during the past years, mainly because of their potential applications as host molecules in the design of suprastructures ${ }^{2}$ and porous materials. ${ }^{3}$ The 2,2'-dioxybiphenyl spirocyclotriphosphazenes having unsubstituted chlorine atoms $\left[\mathrm{N}_{3} \mathrm{P}_{3} \mathrm{Cl}_{4}\left(\mathrm{O}_{2} \mathrm{C}_{12} \mathrm{H}_{8}\right)\right]$ and $\left[\mathrm{N}_{3} \mathrm{P}_{3} \mathrm{Cl}_{2}\left(\mathrm{O}_{2} \mathrm{C}_{12} \mathrm{H}_{8}\right)_{2}\right]^{4}$ are very convenient synthetic intermediates to obtain numerous derivatives functionalized with a variety of chemical functions supported by many aryloxy, ${ }^{5,6}$ amino, ${ }^{5,7}$ and thiophenoxy ${ }^{8}$ groups, including transition metal complexes ${ }^{9}$ or NLO chromophores ${ }^{10}$. They have also been used to formed polycondensation polymers with various bifunctional reagents ${ }^{11}$.

In a recent letter we reported a simple synthetic methodology to incorporate persistent magnetic radicals derived from the TTM series [tris $(2,4,6-$ trichlorophenyl)methyl radical] to the spirocyclic phosphazenes, anchoraged to phosphorus atoms through an oxygen. ${ }^{12}$ Therefore, stable magnetic spirocyclic phosphazenes $\mathbf{1}$ and $\mathbf{2}$ were prepared from dichlorobis $\left(2,2^{\prime}\right.$-dioxybiphenyl) derivative $\left[\mathrm{N}_{3} \mathrm{P}_{3} \mathrm{Cl}_{2}\left(\mathrm{O}_{2} \mathrm{C}_{12} \mathrm{H}_{8}\right)_{2}\right] 3$ and phenolic radical 4 (Chart 1). The study of their EPR spectral properties revealed some exchange and dipolar interactions between radical centers through the $-\mathrm{O}-\mathrm{P}-\mathrm{O}-$ bond. The stability of these carbon centered radicals is due to steric hindrance of the 2,6dichlorophenyl substituents around the trivalent $\mathrm{sp}^{2}$-carbon atom. ${ }^{13}$ The incorporation of more stable radicals of the TTM series in phosphazenes should facilitate the measurement of the degree of interaction between the exo ring substituents that is allowed through the P$\mathrm{N}$ bonds of the ring. This is interesting because it is accepted that there is no electron delocalization in the $-\mathrm{N}=\mathrm{P}-\mathrm{N}=\mathrm{P}-\mathrm{N}=\mathrm{P}$ - formally conjugated ring system. ${ }^{14,15}$ In this context, EPR evidence of induced spin density into the cyclic triphosphazene in a spirocyclic 
phenalenyl radical- and phosphaverdazyl radical-cyclophosphazene hybrids have been reported. ${ }^{16 a, b}$ Following our efforts to incorporate more radicals in cyclophosphazene, now we report the preparation of the related multiradical cyclophosphazenes 5 and $\mathbf{6}$ (Chart 2) and the study of their spectral and electrochemical properties. On the other hand, these results open the possibility to incorporate magnetic properties into polymeric phosphazenes $\left(-\mathrm{N}=\mathrm{PR}_{2}-\right)_{\mathrm{n}}$ as candidates for ferromagnetic interactions.

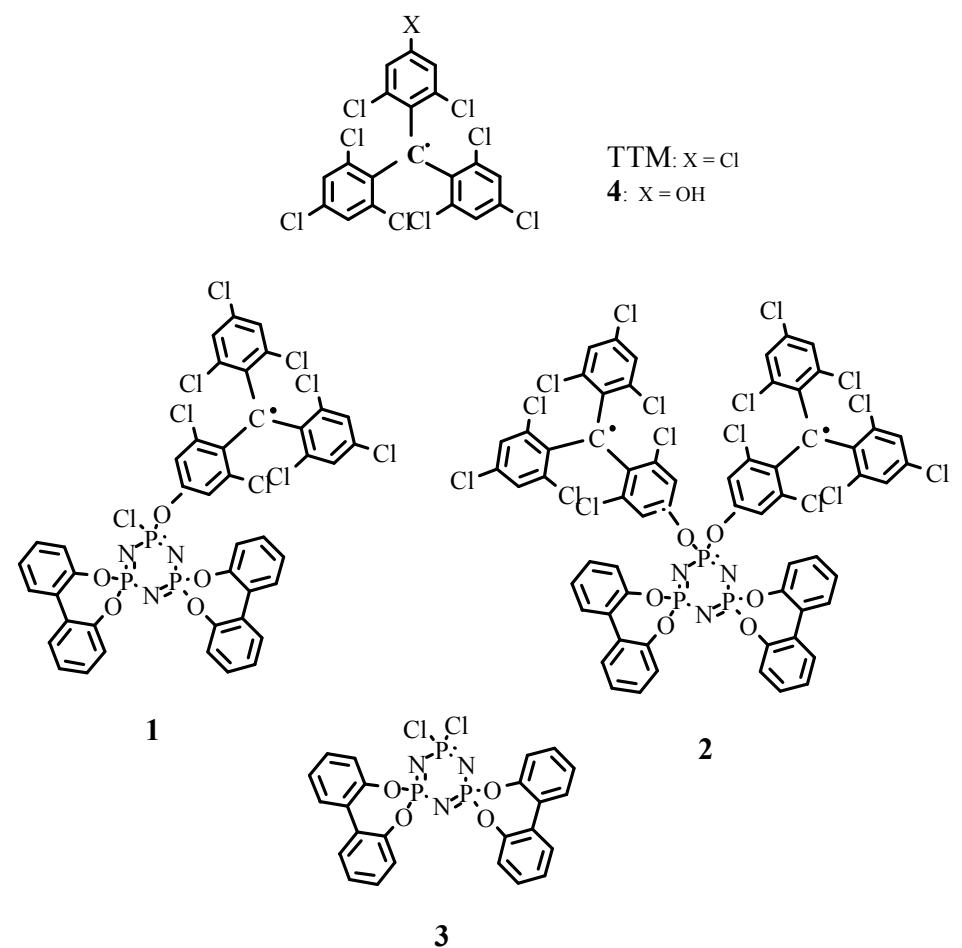

\section{Chart 1}

\section{Results}

The reaction of tetrachloro-2,2'-dioxybiphenyl-cyclotriphosphazene (7) with phenolic radical 4, in the presence of cesium carbonate, gave, after column 
chromatography, the multiradical spirocyclic phosphazenes 5 and 6. These red solids showed characteristic radical bands in the ultraviolet-visible similar to other radicals of the TTM series. ${ }^{13}$ As reported before ${ }^{12}$, the electronic spectrum of monoradical $\mathbf{1}$ and diradical 2 in $\mathrm{CHCl}_{3}$ (Table 1, Figure 1) showed strong absorptions at $372 \mathrm{~nm}$ and weak absorptions around 480 and $535 \mathrm{~nm}$ in analogy with the spectrum of TTM radical, being the absortivities of $\mathbf{2}$ practically twice those of $\mathbf{1}$. The spectra of $\mathbf{5}$ and $\mathbf{6}$ show the same characteristic bands with absortivities approximately three and four times the values for radical TTM. Similar as in $\mathbf{1}$ and $\mathbf{2},{ }^{12}$ red solutions of $\mathbf{5}$ and $\mathbf{6}$ in $\mathrm{CHCl}_{3}$ gave stable and dark blue solutions of the trication $\mathbf{5}^{3+}\left[\lambda_{\max }\left(\varepsilon, \mathrm{dm} \mathrm{mol}^{-1} \mathrm{~cm}^{-1}\right), 650(126800)\right](90 \%$ recovered after $24 \mathrm{~h}$ ) and tetracation $6^{4+}\left[\lambda_{\max }(\varepsilon), 651(160500)\right]$ (quantitatively recovered after $24 \mathrm{~h}$ ), respectively, upon treatment with $\mathrm{SbCl}_{5}$.

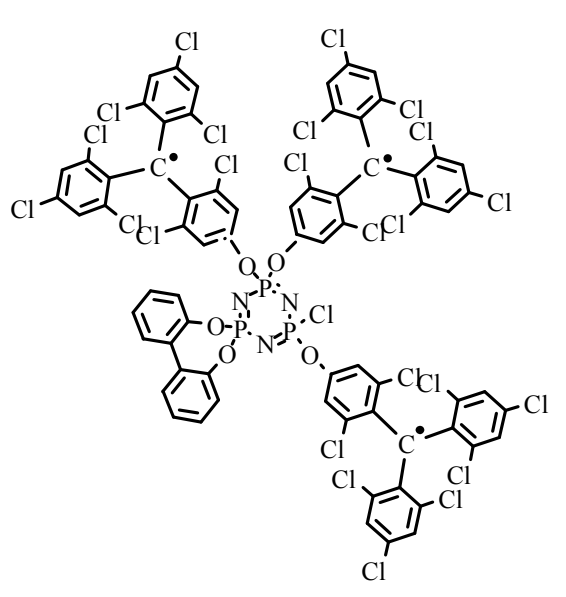

5

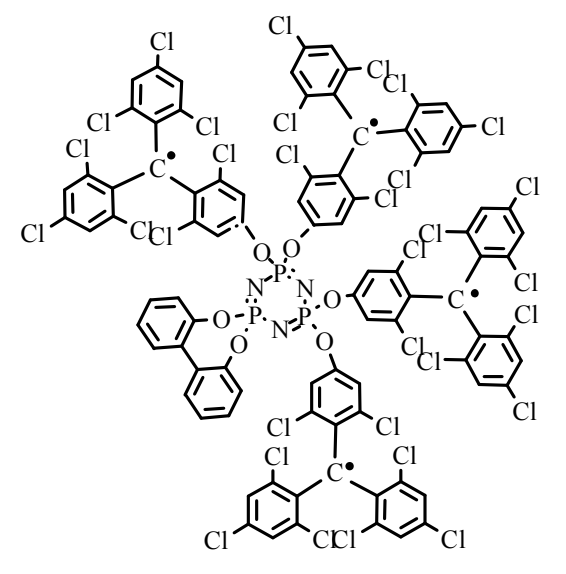

6

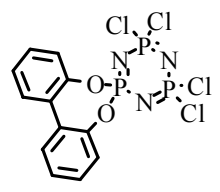

7

Chart 2 
Table 1. UV-Vis data ${ }^{\mathrm{a}}$ and redox potentials by cyclic voltammetry ${ }^{\mathrm{b}}$ for polyradicals $\mathbf{1}, \mathbf{2}, \mathbf{5}, \mathbf{6}$

\begin{tabular}{|c|c|c|c|c|c|c|}
\hline & & $\lambda_{\max }(\varepsilon)^{\mathrm{c}} \mathrm{nm}$ & & $E^{o} \mathrm{~N} v s . \mathrm{SSCE}$ & $E_{p}^{c}, E_{p}^{a(d)}$ & $\Delta E_{p}$ \\
\hline 1 & $372(34800)$ & $480(\mathrm{sh})(880)$ & $536(800)$ & -0.55 & $-0.65,-0.46$ & 0,19 \\
\hline 2 & $372(69000)$ & $489(1680)$ & $535(1630)$ & -0.57 & $-0.64,-0.50$ & 0.14 \\
\hline 5 & $372(113000)$ & $489(2570)$ & $536(2600)$ & -0.61 & $-0.75,-0.48$ & 0.27 \\
\hline 6 & $372(138200)$ & $489(3370)$ & $536(3480)$ & -0.70 & $-0.90,-0.49$ & 0.41 \\
\hline
\end{tabular}

${ }^{\mathrm{a}}$ In $\mathrm{CHCl}_{3}$ solution; ${ }^{\mathrm{b}}$ in $\mathrm{CH}_{2} \mathrm{Cl}_{2}$ with $0.1 \mathrm{M} \mathrm{TBAP}$ at $25^{\circ} \mathrm{C} ;{ }^{\mathrm{c}} \varepsilon$ in $\mathrm{L} \mathrm{mol}^{-1} \mathrm{~cm}^{-1}$ at $22{ }^{\circ} \mathrm{C}^{\text {d }}$ peak potential values at $v=200 \mathrm{mV} \mathrm{s}^{-1}$.

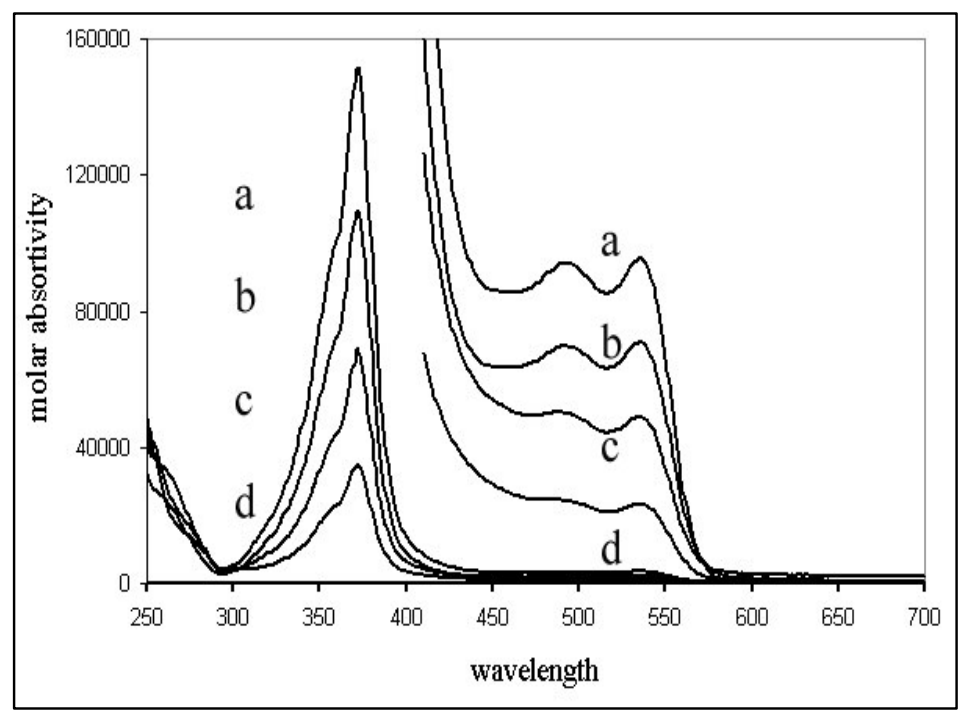

Figure 1. UV-vis spectra of polyradicals 1 (d), 2 (c), 5 (b), and 6 (a) in $\mathrm{CHCl}_{3}$ solution at $22{ }^{\circ} \mathrm{C}$; the less energetic absorptions are enlarged 30 times. Wavelength $(\lambda)$ in $\mathrm{nm}$, and absortivities $(\varepsilon)$ in $\mathrm{dm} \mathrm{mol}^{-1} \mathrm{~cm}^{-1}$.

EPR spectra of the four polyradicals $1,2,5$, and $\mathbf{6}$ in diluted $\left(\sim 10^{-3} \mathrm{M}\right)$ and degassed solutions are depicted in Figure 2 (left), and their simulations ${ }^{17}$ (right) have 
been performed by using the parameters in Table 2 . The spectrum of $\mathbf{1}$ in $\mathrm{CCl}_{4}$ solution at $293 \mathrm{~K}$ exhibits an overlapped doublet of septets due to hyperfine coupling with a phosphorus nucleus and six meta-hydrogens.. The spectrum of a MeTHF solution of 2 at r.t. gives rise to a broad doublet with hyperfine coupling with a phosphorus nucleus and 12 hydrogens. The coupling with the phosphorus in $\mathbf{2}$ is slightly lower than that of the monoradical $\mathbf{1}$, and the coupling with 12 hydrogens is half the value of the coupling with the 6 hydrogens in 1 suggesting that that the electron exchange interaction is larger than the hyperfine interaction $\left(|J|>\left|a_{\mathrm{H}}\right|\right)$. The resolution of the spectra of polyradicals $\mathbf{5}$, and $\mathbf{6}$ is drastically reduced suggesting likewise that the electron exchange interaction is larger than hyperfine interactions with phosphorus and hydrogens $\left(|J|>\left|a_{\mathrm{P}}\right|\right.$ and $|J|>$ $\left.\left|a_{\mathrm{H}}\right|\right)$ and, consequently, $a_{\mathrm{P}}$ and $a_{\mathrm{H}}$ values should be much lower than those of the diradical 2. Therefore, the spectrum of 5 and $\mathbf{6}$ in well-degassed MeTHF solutions at $183 \mathrm{~K}$ and $293 \mathrm{~K}$ exhibit broad and distorted singlets. Simulated spectra which best fit to them, depicted in Figure 2, have been estimated with the parameters displayed in Table 2. In triradical 5 two hyperfine coupling constants (hfc) with phosphorus nuclei which are two-third of the hfc value of diradical 2 and one-third of that of monoradical 1, one hfc with the nitrogen in the exchange pathway (P-N-P), and one hfc with 18 hydrogens one-third of the hfc value of monoradical 1. In tetraradical 6 one hfc with two phosphorus, one hfc with the nitrogen in the exchange pathway (P-N-P), and one hfc with 24 hydrogens which are half the values of $a_{\mathrm{P}}$ and $a_{\mathrm{H}}$ in diradical 2. Values of hfc for phosphorus and hydrogen nuclei of $\mathbf{5}$ and $\mathbf{6}$ are the expected values for fast electron exchange between the three TTM moieties in $\mathbf{5}$ and between the four TTM moieties in $\mathbf{6}$, as predicted by the theory. 
Table 2. EPR parameters for polyradicals 1, 2, 5, and $\mathbf{6}$ in solution

\begin{tabular}{|c|c|c|c|}
\hline & $G$ & $a(\mathrm{G})$ & $\Delta H_{p p}(\mathrm{G})$ \\
\hline \multirow[t]{2}{*}{$\mathbf{1}^{\mathrm{a}}$} & 2.0032 & $5.25(1 \mathrm{P})$ & 0.8 \\
\hline & & $1.25(6 \mathrm{H})$ & \\
\hline \multirow[t]{2}{*}{$2^{\mathrm{a}}$} & 2.0032 & $4.20(1 \mathrm{P})$ & 1.5 \\
\hline & & $\# 0.62(12 \mathrm{H})$ & \\
\hline \multirow[t]{4}{*}{$5^{\mathrm{b}}$} & 2.0029 & $2.8(1 \mathrm{P})$ & 0.6 \\
\hline & & $1.75(1 \mathrm{P})$ & \\
\hline & & $\# 0.6(1 \mathrm{~N})$ & \\
\hline & & $\# 0.42(18 \mathrm{H})$ & \\
\hline \multirow[t]{3}{*}{$6^{\mathrm{c}}$} & 2.0026 & $2.1(2 \mathrm{P})$ & 1.0 \\
\hline & & $\# 0.6(1 \mathrm{~N})$ & \\
\hline & & $\# 0.31(24 \mathrm{H})$ & \\
\hline
\end{tabular}

MeTHF at room temperature 


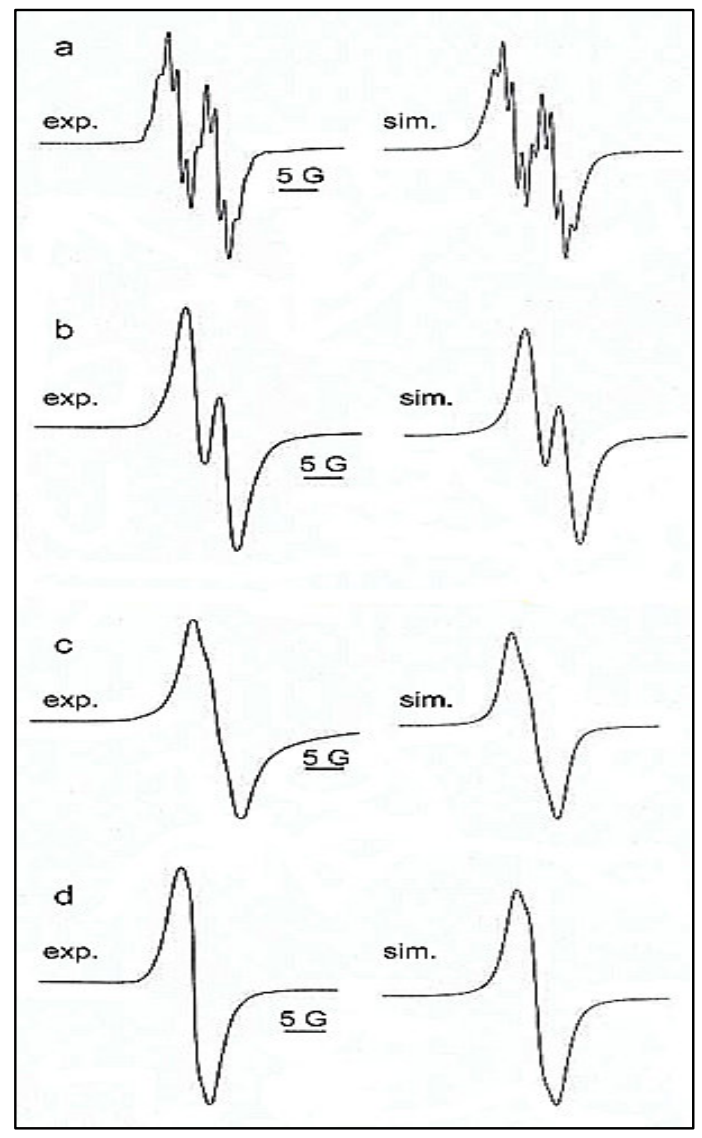

Figure 2. Experimental and simulated spectra of (a) radical 1 in $\mathrm{CCl}_{4}$ at r.t., (b) diradical 2 in $\mathrm{CCl}_{4}$ at r.t., (c) triradical 5 in MeTHF at $183 \mathrm{~K}$, and (d) tetraradical 6 in MeTHF at r.t.

As previously reported ${ }^{12}$, the spectrum of diradical 2 taken in solid MTHF solution at $110 \mathrm{~K}$ shows a broad doublet due to the phosphorus splitting with weak fine structure in the $\Delta m_{s}= \pm 1$ region due to the dipolar spin electron exchange interaction, being the zero-field splitting parameters $|D / h c|=0.0016 \mathrm{~cm}^{-1}$ and $|E / h c|=0.2 \cdot 10^{-4} \mathrm{~cm}^{-1}$. Confirmation of the triplet state was provided by the small doublet in the $\Delta m_{s}= \pm 2$ region which obeyed the Curie's law between 4 and $80 \mathrm{~K}$, consistent with a triplet ground state or a degeneracy of singlet and triplet states. 
Triradical 5 shows in solid MeTHF solution at $11 \mathrm{~K}$ a broad $\left(\Delta H_{p p}=7.4 \mathrm{G}\right)$ doublet in the $\Delta m_{s}= \pm 1$ region with a very weak fine structure corresponding to a very low value of the zero-field parameter, $|D / h c| \sim 0.0013 \mathrm{~cm}^{-1}$, and a doublet $(\mathrm{g}=4.005$; $\Delta H_{p p} \sim 6 \mathrm{G}$ ) in the $\Delta m_{s}= \pm 2$ (Figure 3). Moreover, the presence in this region of a very weak but broad $\left(\Delta H_{p p} \sim 32 \mathrm{G}\right)$ doublet at $\mathrm{g}=4.28$ suggests the coexistence of a different multiplet state. In any case no signal is observed from the $\Delta m_{s}= \pm 3$ transition. The intensity of the $\mathrm{g}=4.005$ signal increased as the temperature was decreased from 85 to $4 \mathrm{~K}$ (Figure 5) in agreement with the Curie's law. This result is consistent with a ground state of multiplicity $S \geq 1$, or a degeneracy of states with different multiplicities.

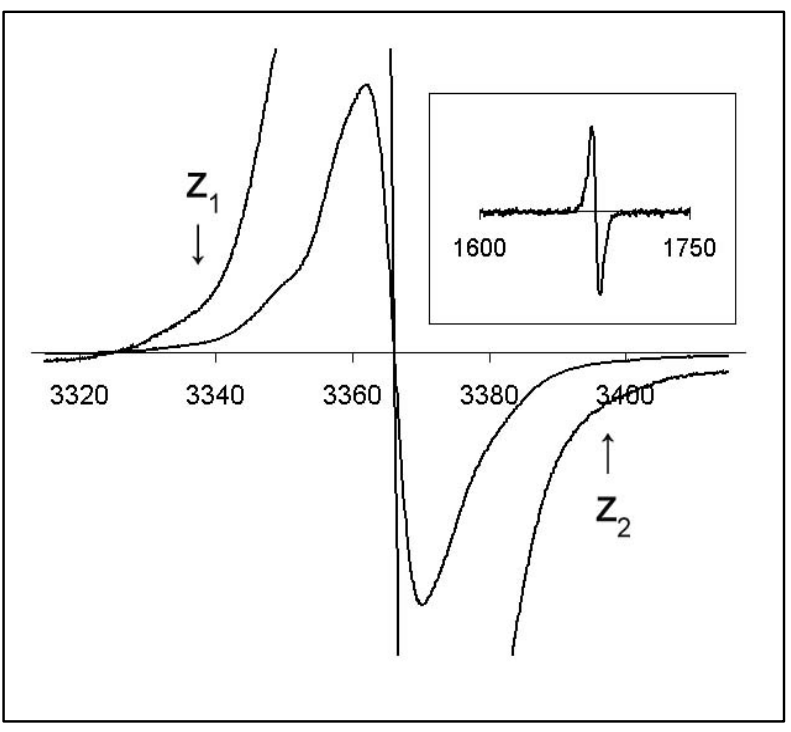

Figure 3. EPR spectrum in a glassy solution of triradical 5 in MeTHF at $11 \mathrm{~K}$ with a separation of the outermost fine structure field components $H_{\mathrm{z} 2}-H_{\mathrm{z} 1} \sim 55 \mathrm{G}$. The inset represents the signal of the $) m_{\mathrm{s}}= \pm 2$ transition at $11 \mathrm{~K}$ 


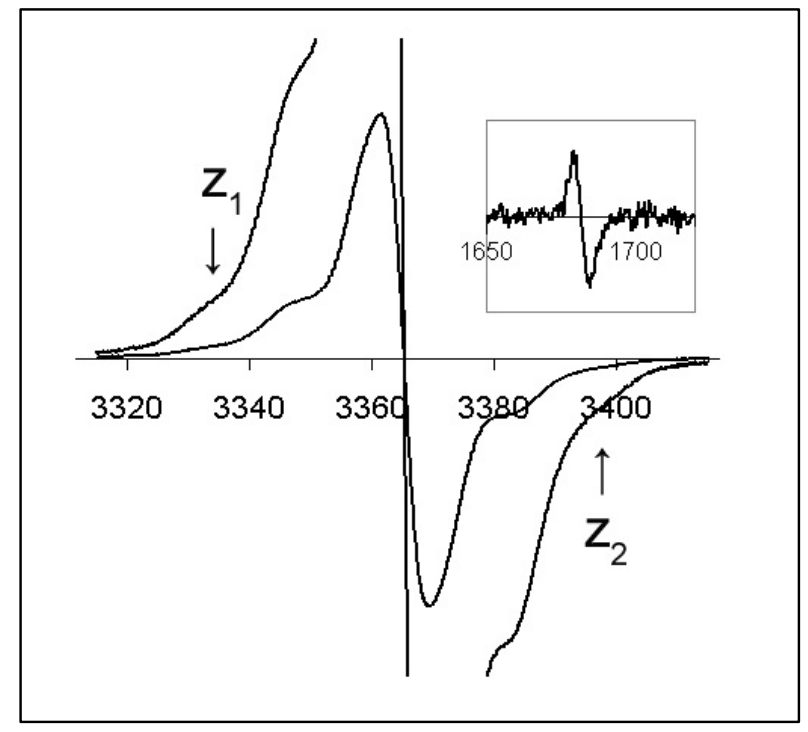

Figure 4. EPR spectrum in a glassy solution of tetraradical 6 in MeTHF at $4 \mathrm{~K}$ with a separation of the outermost fine structure field components $H_{\mathrm{z} 2}-H_{\mathrm{z} 1} \sim 63 \mathrm{G}$.. The inset represents the signal of the $) m_{\mathrm{s}}= \pm 2$ transition at $4 \mathrm{~K}$

The spectrum of a solid solution of tetraradical 6 in MeTHF at $4 \mathrm{~K}$ shows in the $\Delta m_{s}= \pm 1$ region a broad $\left(\Delta H_{p p}=8.0 \mathrm{G}\right)$ doublet with fine structure (Figure 4). Considering a multiplicity of $\mathrm{S}=2$, from the outermost shoulders, $H_{\mathrm{z} 1}$ and $H_{\mathrm{z} 2}$, a zerofield parameter, $|D / h c| \sim 0.0010 \mathrm{~cm}^{-1}$ is derived. In the $\Delta m_{s}= \pm 2$, a doublet $(\mathrm{g}=4.007$; $\Delta H_{p p} \sim 5 \mathrm{G}$ ) confirms the existence of a multiplet state which does not obey the Curie's law as depicted in Figure 5. 


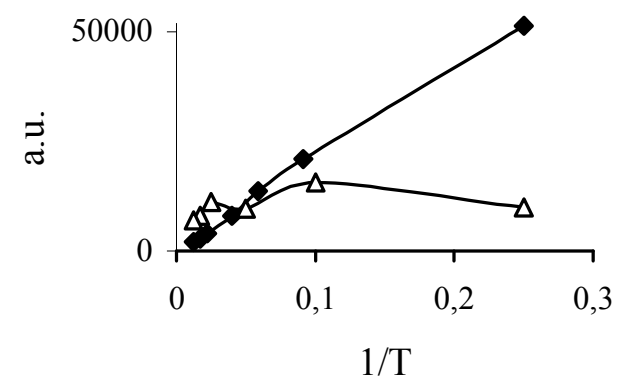

Figure 5. Temperature dependence of the $) m_{\mathrm{s}}$ $= \pm 2$ signal intensities for triradical $\mathbf{5}(\bullet)$ and tetraradical $6(\Delta)$ in MeTHF from 4 to $85 \mathrm{~K}$

Cyclic voltammetries for the reduction of polyradicals $\mathbf{1 , 2}, \mathbf{5}$, and $\mathbf{6}\left(\sim 10^{-3} \mathrm{M}\right)$ in $\mathrm{CH}_{2} \mathrm{Cl}_{2}$ containing tetra- $n$-butylammonium perchlorate (TBAP) $\left(\sim 10^{-1} \mathrm{M}\right)$ at $25^{\circ} \mathrm{C}$ exhibit one redox couple, $\mathrm{R}_{1} / \mathrm{O}_{1}$, with standard potentials, $E^{o}$, as shown in Table 2. Values of peak potentials for the anodic and cathodic processes and values of $\Delta \mathrm{E}_{\mathrm{p}}$ are also displayed in Table 2. These redox processes were associated to one-, two-, three-, and four-electron reductions to the corresponding polyanions $\mathbf{1}^{-}, \mathbf{2}^{\mathbf{2 -}}, \mathbf{5}^{3-}$ and $\mathbf{6}^{\mathbf{4 -}}$. The waves are broad and there is a slightly shift to more negative values on going from mono- to tetraradical. Electrochemical reduction of TTM radical in the same conditions gives a redox couple at $E^{o}=-0.66 \mathrm{~V}$.

Molar magnetic susceptibilities $\left(\chi_{\mathrm{M}}\right)$ of triradical 5 and tetraradical 6 were measured in the temperature range $4-300 \mathrm{~K}$ with a SQUID magnetometer operating in a field-strength of $20 \mathrm{kOe}$. The data $\left(\chi_{M}=\chi_{S}-\chi_{\text {dia }}-\chi_{\text {holder }}\right)$ were corrected for the magnetization of the sample holder and for the diamagnetic susceptibilities of the molecules $\left(-1194.6 \cdot 10^{-6} \mathrm{~cm}^{3} \mathrm{~mol}^{-1}\right.$ for triradical 5 and $-1494.3 \cdot 10^{-6} \mathrm{~cm}^{3} \mathrm{~mol}^{-1}$ for tetraradical 6, using Pascal's constants). The thermal variation of the molar effective 
magnetic moment in Bohr magnetons in Figure 6 is given by $\mu_{\text {eff }}=2.828\left(\chi_{M} T\right)^{1 / 2}$. Experimental data for both species fit reasonably well with very low interaction values $\left(J_{i}\right)$ among radical centers. Different combinations of these parameter values gave good fittings with the experimental results, including or not a Curie temperature, which accounts for the intermolecular interactions. In any case, the energetic distance among the different spin states, if any, should be very low so that they are similarly populated at temperatures as low as $150 \mathrm{~K}$. Therefore, $\mathbf{5}$ and $\mathbf{6}$ practically behave as molecules with three and four independent radical centers, respectively, at temperatures down to $150 \mathrm{~K}$, and at lower temperatures, $\mu_{\mathrm{eff}}$ decrease due to intra- and/or intermolecular antiferromagnetic interactions.

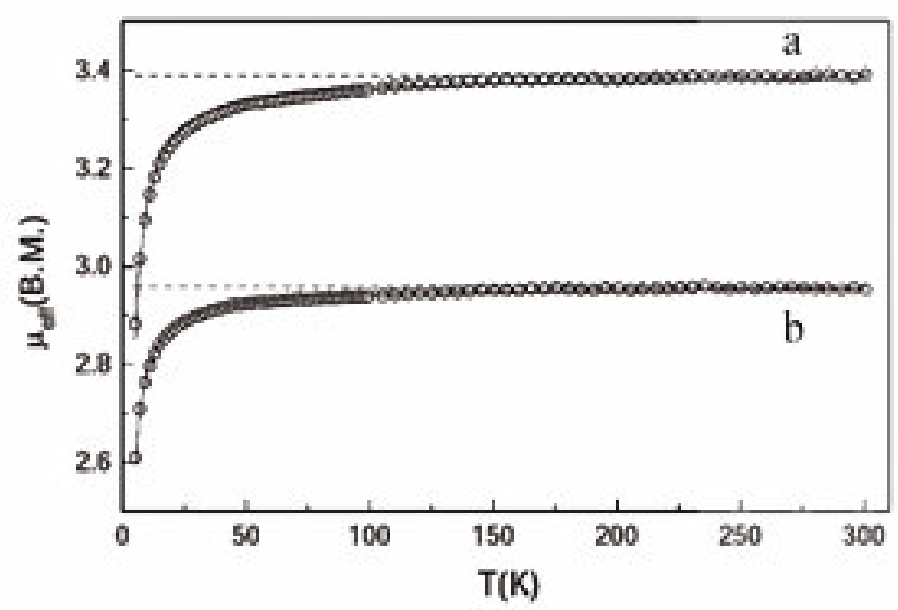

Figure 6. Thermal variation of $\mu_{\mathrm{eff}} / \mu_{\mathrm{B}}$ for a) tetraradical $\mathbf{6}$ and b) triradical 5 from samples measured in a SQUID magnetometer operating with a field strength of $20 \mathrm{kOe}$. The dashed horizontal lines correspond to the theoretical functions for (a) four and (b) three independent radical centers, considering the purity factors for both samples: (a), $\mu_{\mathrm{eff}}=4^{1 / 2}$ $\cdot 1.73 \cdot 0.957^{1 / 2}=3.38$; (b), $\mu_{\mathrm{eff}}=3^{1 / 2} \cdot 1.73 \cdot 0.972^{1 / 2}=2.95$. 


\section{Discussion}

We have prepared macromolecular polyradicals $\mathbf{5}$ and $\mathbf{6}$ following the same methodology used to introduce one and two persistent magnetic species derived of TTM series into a cyclotriphosphazene ring. These processes without impairment of the radical character of the molecule are possible due to the stability of the radical center attributed to steric shielding by the six chlorines surrounding the trivalent carbon. Both polyradicals have been obtained in solid state, and their visible spectra, very similar to those of mono- and diradical $\mathbf{1}$ and $\mathbf{2}$, show absortivities nearly proportional to the number of radical centers in the molecule. Electrochemical behavior of $\mathbf{5}$ and $\mathbf{6}$ shows a three-electron and four-electron single and broad peaks, respectively, in their cyclic voltammograms. Concerning the values of the cathodic peak potentials of the four polyradicals in Table 2, there is a slightly shift to more negative values on going from mono- to tetraradical. This fact and the width of the cathodic peaks in the CV of $\mathbf{5}$ and $\mathbf{6}$ suggest the existence of simultaneous multiple one-electron reduction processes for these systems.

As indicated above, the epr spectra of isotropic solutions of 2, 5 and $\mathbf{6}$ show presumably a rapid electron exchange among two, three and four radical centers, respectively, as it is showed by simulation. While this exchange in diradical 2, where both radical centers are bonded at the same phosphorus atom, arises through the O-P-O bond, in 5 and $\mathbf{6}$ the exchange involves also at least part of the cycle, through the multiple bond $\mathrm{P}=\mathrm{N}-\mathrm{P}$. In glassy solutions, the zero-field parameters calculated in the $\Delta m_{s}= \pm 1$ region are very small, either in $\mathbf{5}$ or in $\mathbf{6}$, showing that the dipolar spin-spin interactions are also very weak. This is in part a consequence of the propeller-like conformation adopted by the radicals of the TTM series, with a significant inhibition of 
the delocalization of the free electron in the aromatic rings, and in part a consequence of the saturated $\mathrm{C}-\mathrm{O}-\mathrm{P}$ bonds which reduce the extension of the $\pi$ system.

As indicated above, with the effective magnetic moments of $\mathbf{5}$ and $\mathbf{6}$ alone it is not possible to differentiate between inter- and intramolecular contributions in the decrease of the values at lower temperatures. In fact, experimental results in Figure 6 have been fitted without including a Curie temperature: parameter values for triradical $5, \mathrm{~J}_{1}=2.2 \pm 0.5 \mathrm{~K} ; \mathrm{J}_{2}=\mathrm{J}_{3}=0.6 \pm 0.5 \mathrm{~K}$, considering a purity factor $\mathrm{x}=0.972$, being $\mathrm{J}_{1}$ the interaction constant between spins in the same phosphorus atom and $J_{2}$ and $J_{3}$ the interaction between spins in different phosphorus atoms. Therefore, the strong decrease of the $\mu_{\mathrm{eff}}$ values may suggest antiferromagnetic couplings within the molecule rather than intermolecular interactions. However, the increase of the $\Delta m_{s}= \pm 2$ signal from 85 $\mathrm{K}$ to $4 \mathrm{~K}$ in the glassy solution of triradical 5 suggests the presence of triplet or quadruplet states at low energies. As reported in the diradical 2, the presence of a low energy triplet state is possible if both odd electrons are ferromagnetically coupled. In the case of triradical 5, a quadruplet is possible if all three spins interact ferromagnetically to each other, and a triplet is also possible if two spins are ferromagnetically coupled as in 2 , and the coupling with the third electron is negligible. But in both cases, the $\mu_{\text {eff }}$ should tend to values of $3.87 \mathrm{MB}\left[\mathrm{g} \cdot[3 / 2(3 / 2+1)]^{1 / 2}\right]$ for quadruplet and $3.32 \mathrm{MB}$ $\left[\mathrm{g} \cdot[1(1+1)+1 / 2(1 / 2+1)]^{1 / 2}\right]$ for a system with triplet and doublet, and not to the experimental value of $2.95 \mathrm{MB}$, that is very close to the theoretical value of $3 \mathrm{MB}$ $\left[g \cdot[1 / 2(1 / 2+1) \cdot 3]^{1 / 2}\right]$ expected for three independent radical centers. The simplest explanation of both results, EPR and magnetic data for $\mathbf{5}$ would seem to be that the spin states are in fact degenerate and that the magnetic susceptibility data reflect weak intermolecular interactions and not intramolecular. In tetraradical $\mathbf{6}$, the temperaturedependent experiments do not show a linear relation for the intensity of the $\Delta m_{s}= \pm 2$ 
signal and, therefore, the ground state is identified with a singlet state. However, as the $\mu_{\text {eff }}$ values tend to $3.38 \mathrm{BM}$ at $150 \mathrm{~K}$, value for four independent radical centers, states of higher multiplicity are energetically very close to the singlet, or practically degenerated.

\section{Conclusions}

In summary, although the dipolar interactions in the EPR of glassy solutions of polyradicals $\mathbf{5}$ and $\mathbf{6}$ are too weak to clearly show an induced spin polarization in the phosphazene ring, the rapid electron exchange interaction in their fluid spectra suggests some kind of electronic communication among the radical centers through the multiple NP bonds.

\section{Experimental section}

General procedures. All the reactions were carried out under nitrogen. $\mathrm{Cs}_{2} \mathrm{CO}_{3}$ (Aldrich) was dried at $140{ }^{\circ} \mathrm{C}$ prior to use. THF was treated with $\mathrm{KOH}$ and distilled twice from sodium in the presence of benzophenone. The spirocyclic phosphazene $\left[\mathrm{N}_{3} \mathrm{P}_{3} \mathrm{Cl}_{4}\left(\mathrm{O}_{2} \mathrm{C}_{12} \mathrm{H}_{8}\right)\right]$ (7) was prepared as described elsewhere. ${ }^{6}$ The IR spectra were recorded for all new compounds, and electronic spectra were recorded for polyradicals. EPR spectra were recorded with a spectrometer working in the $\mathrm{X}$ band, using a continuous-flow liquid nitrogen temperature-controller to obtain spectra at temperatures down to $180 \mathrm{~K}$, and with a continuous-flow liquid helium cryostat and a temperaturecontroller system to obtain EPR spectra at lower temperatures down to $4 \mathrm{~K}$. Samples of polyradicals 5 and $\mathbf{6}$ were prepared in quartz EPR tubes and degassed before being inserted into the EPR cavity. Handling of radicals in solution was performed in the dark. Magnetic susceptibility data $\left(\chi_{\mathrm{S}}\right)$ for microcrystalline samples of polyradicals were 
measured from 4 to $300 \mathrm{~K}$ with a SQUID magnetometer operating with a field strength of $20 \mathrm{kOe}$. The cyclic voltammetric (CV) experiments were carried out in a threeelectrode cell. A platinum $(\mathrm{Pt})$ disk with an area of $0.093 \mathrm{~cm}^{2}$ was used as the working electrode and a Pt wire as the counter electrode. The reference electrode was a calomel electrode (SSCE) with a NaCl-saturated aqueous solution, submerged in a salt bridge of the same electrolyte, which was separated from the cell by a Vycor membrane. Solutions of polyradicals 5 and $6\left(\sim 10^{-3} \mathrm{M}\right)$ in $\mathrm{CH}_{2} \mathrm{Cl}_{2}$ containing tetrabutylammonium perchlorate $(0.1 \mathrm{M})$ as background electrolyte were studied by $\mathrm{CV}$. The volume of all test solutions was $25 \mathrm{~mL}$. The $\mathrm{CV}$ measurements were performed with a standard equipment consisting of an universal programmer, a potentiostat, and a $\mathrm{X}-\mathrm{Y}$ recorder. Cyclic voltammograms of all solutions were recorded with scan rates $(v)$ ranging from 20 to $200 \mathrm{mV} \mathrm{s}^{-1}$.

Synthesis of the spirotriphosphazenes 5 and 6: A mixture of $\left[\mathrm{N}_{3} \mathrm{P}_{3} \mathrm{Cl}_{4}\left(\mathrm{O}_{2} \mathrm{C}_{12} \mathrm{H}_{8}\right)\right](7)(0.20 \mathrm{~g}, 0.44 \mathrm{mmol})$, (2,6-dichloro-4-hydroxyphenyl)bis(2,4,6trichlorophenyl)methyl radical (4) $(1.07 \mathrm{~g}, 2.0 \mathrm{mmol})$ and $\mathrm{Cs}_{2} \mathrm{CO}_{3}(1.0 \mathrm{~g}, 3.08 \mathrm{mmol})$ in THF $(20 \mathrm{~mL})$ was stirred at room temperature for $15 \mathrm{~h}$. The resulting mixture was filtered from a green precipitate, and the solution was evaporated in vacuum to give an orange residue which was chromatographed in silica gel eluting with carbon tetrachloride to give: spirocyclotriphosphazene $6(0.57 \mathrm{~g} ; 53 \%)$ : IR $(\mathrm{KBr})<3100(\mathrm{w})$, $1575(\mathrm{~m}), 1554(\mathrm{~m}), 1525(\mathrm{~m}), 1370(\mathrm{~m}), 1180(\mathrm{~s}), 1096(\mathrm{w}), 973(\mathrm{~m}), 858(\mathrm{~m}), 812(\mathrm{~m})$ $\mathrm{cm}^{-1}$. Anal. Calc. for $\mathrm{C}_{88} \mathrm{H}_{32} \mathrm{Cl}_{32} \mathrm{~N}_{3} \mathrm{O}_{6} \mathrm{P}_{3}: \mathrm{C}, 43.1 ; \mathrm{H}, 1.3 ; \mathrm{Cl}, 46.2 ; \mathrm{N}, 1.7$. Found: $\mathrm{C}$, 43.1; H, 1.3; Cl, 46.8; N, 1.7; spirocyclotriphosphazene $5(0.36 \mathrm{~g} ; 42 \%)$ : IR $(\mathrm{KBr})<$ 3100(w), 1575(m), 1554(m), 1525(m), $1371(\mathrm{~m}), 1209(\mathrm{~m}), 1180(\mathrm{~s}), 1096(\mathrm{w}), 975$ 
(m), $858(\mathrm{~m}), 811(\mathrm{~m}) \mathrm{cm}^{-1}$. Anal. Calc. for $\mathrm{C}_{69} \mathrm{H}_{26} \mathrm{Cl}_{25} \mathrm{~N}_{3} \mathrm{O}_{5} \mathrm{P}_{3}$ : C, 42.4; $\mathrm{H}, 1.3 ; \mathrm{Cl}, 45.3$;

N, 2.1. Found: C, 43.1; H, 1.6; N, 2.0.

Acknowledgment. Financial support for this research from the MCYT (Spain) through projects BQU2000-0789-C02-02 and BQU2001-3676, and FICYT, project PB.EXPO115 is gratefully acknowledged. We also thank the EPR services of the Centre d'Investigació i Desenvolupament (CSIC) and of the University of Barcelona for recording the spectra.

\section{References}

(1) Allcock, H. R.; Diefenbach, U.; Pucher, S. R. Inorg. Chem. 1994, 33, 3091-3095.

(2) Allcock, H. R.; Primrose, A. P.; Sunderland, N. J.; Rheingold, A. L.; Guzei, I. A.;

Parvez, M. Chem. Mater. 1999, 11,1243-1252. Allcock, H. R.; Sunderland, N. J.;

Primrose, A. P.; Rheingold, A. L.; Guzei, I. A.; Parvez, M. Chem. Mater. 1999, 11

2478-2485. Allcock, H. R.; Primrose, A. P.; Silverberg, E. N.; Visscher, K. B.;

Rheingold, A. L.; Guzei, I. A. Parvez, M. Chem. Mater. 2000, 12, 2530-2536.

(3) Sozzani, P.; Comotti, A.; Simonutti, R.; Meersmann, T.; Logan, J. W.; Pines, A.

Angew. Chem. Int. Edit. 2000, 39, 2695-2698

(4) Amato, M. E; Carriedo, G. A.; García Alonso, F. J.; García Alvarez, J. L.;

Lombardo, G. M.; Pappalardo, G. C. Chem. Soc. Dalton Trans. 2002, 3047-3053 references therein.

(5) Pelc, R. A.; Brandt, K.; Jedlinski Z. Phosphorous, Sulfur and Silicon. 1990, 47, 375382 
(6) Carriedo, G. A.; Fernández Catuxo, L.; García Alonso, F. J.; Gómez Elipe, P.;

González, P. A. Macromolecules. 1996, 29, 5320-5325

(7) Carriedo, G. A.; Fidalgo Martínez, J. I.; García Alonso, F. J.; Rodicio González, E.; Presa Soto, A. Eur. J. Inorg. Chem. 2002, 1502-1510.

(8) Carriedo, G. A.; García Alonso, F. J.; López Vizcaíno, S.; Diaz Valenzuela, C.; Yutronic, N.Phosphorus, Sulfur and Silicon 2003, 178, 1549-1555.

(9) Carriedo, G. A.; García Alonso, F. J.; García, J. L.; Carbajo, R.; López Ortiz, F. Eur. J. Inorg. Chem. 1999, 1015-1020. Carriedo, G. A.; García Alonso, F. J.; González, P. A.; Gómez Elipe, P. Polyhedron 1999, 18, 2853-2859.

(10) Rojo, G.; Martín, G.; Agulló-López, F.; Carriedo, G. A.; García Alonso, F. J.; Fidalgo Martínez, J. I. Chem. Mater 2000, 12, 3603-3610.

(11) Tunca, U.; Erdogmus, A.; Hizal. G. J. Polym. Sci. Pol. Chem. 2001, 39, $2993-$ 2997. Dez, I.; De Jaeger, R. Phosphorous, Sulfur and Silicon. 1997, 130, 1-14. Dez, I.; Levalois-Mitjaville, J; Grütsmacher, H.; Gramlich, V.; De Jaeger. R. Eur. J. Inorg. Chem. 1999, 1673-1684. Kumar, D.; Gupta , A. D. Macromolecules 1995, 28, 63236329.

(12) Carriedo, G. A.; García Alonso, F. J.; Gómez Elipe, P.; Brillas, E. ; Juliá. L. Org. Lett. 2001, 3, 1625-1628.

(13) a) Armet, O.; Veciana, J.; Rovira, C.; Riera, J.; Castañer, J.; Molins, E.; Rius, J.; Miravitlles, C.; Olivella, S.; Brichfeus, J. J. Phys. Chem. 1987, 91, 5608-5616. b) Teruel, L.; Viadel, Ll.; Carilla, J.; Fajarí, Ll.; Brillas, E.; Sañé, J.; Rius, J.; Juliá, L. J. Org. Chem. 1996, 61, 6063-6066. c) Viadel, Ll.; Carilla, J.; Brillas, E.; Labarta, A.; Juliá, L. J. Mat. Chem. 1998, 8, 1165-1172. d) Carilla, J.; Fajarí, Ll.; Juliá, L.; Riera, J.; Viadel, Ll. Tetrahedron Lett. 1994, 35, 6529-6532. e) Domingo, V. M.; Burdons, X.; 
Brillas, E.; Carilla, J.; Rius, J.; Torrelles, X.; Juliá, L. J. Org. Chem. 2000, 65, 68476855.

(14) Luaña, V.; Martín Pendás, A.; Costales A.; Carriedo, G. A; García Alonso, F. J. J. Phys. Chem. A. 2001, 105, 5280-5291, and references therein.

(15) Breza, M. Polyhedron 2000, 19, 389-397. Breza, M. Theochem 2000, 505, 169177.

(16) a) Haddon, R. C.; Mayo, S. L.; Chichester, S. V.; Marshall, J. H. J. Amer. Chem. Soc. 1985, 107, 7585-7591. Haddon, R. C.; Chichester, S. V.; Mayo, S. L. Inorg. Chem. 1988, 27, 1911-1915. b) Barclay, T. M. ; Hicks, R. G.; Ichimura A. S., Patenaude, G. W. Canad. J. Chem. 2002, 80, 1501-1506.

(17) EPR spectra of fluid solutions were simulated using WINSIM program provided by D. Dulog, Public EPR Software Tools, National Institute of Environmental Health Sciences, Bethesda MD 1996. 